IOSR Journal of Pharmacy

ISSN: 2250-3013, www.iosrphr.org

||| Volume 2 Issue 4 ||| July-August 2012 ||| PP.29-32

\title{
An experimental study to evaluate the effect of instrumental Indian classical and western music therapy on learning and memory in stress induced young rats.
}

\author{
Dr.Harpreet Kour*, Dr.Rajashree Ravishankar, Dr.S.S Goudar. \\ Depart. Of Physiology N Medical College, KLE university, Belgaum.
}

\begin{abstract}
Background: Stress is known to induce alterations in various physiological responses even leading to pathological state. It is known to be linked with memory. The long term stress leads to severity of cognitive deficits. One of the most powerful sources of auditory stimulation in the human brain is provided by music. Listening to music is a complex process for the brain, since it triggers a sequel of cognitive and emotional components with distinct neural substrates.

Objectives: To compare the effect of classical instrumental Indian music on memory of stress induced young rats.

Methods: The rats of age 30 days are stressed by Tube stress for duration of 2 hour per day for 10 days followed by instrumental music therapy. 4 Comparative groups with 6 rats in each group are studied. Then, rats were tested for cognitive changes by Morris water maze, along with age matched control rats.

Results: Stress significantly decreases learning and memory in the rats. However, significant $(p<0.005)$ improvement is observed after the treatment with Indian instrumental classical music among stress induced rats.

Conclusion: Indian instrumental classical music is one of the very cost effective, easily reachable remedy in reliving the negative effects of stress induced cognitive impairments.
\end{abstract}

\section{INTRODUCTION}

Stress is constant in our lives and cannot be avoided ${ }^{1}$. It is known to induce alterations in various physiological responses even leading to pathological state and is known to be linked with memory ${ }^{2}$. It has been known that severe stress lasting weeks or months can impair cell communication in the brain's learning and memory region ${ }^{1}$. The long term stress leads to severity of cognitive deficits ${ }^{3}$. Stress seems to facilitate memory formation when the learning procedure itself is arousing or emotionally valanced, or when learning takes place in a stressful context ${ }^{4}$. Stress is a biologically significant factor that, by altering brain cell properties, can disturb cognitive processes such as learning and memory, and consequently limit the quality of human life ${ }^{5-6}$.

One of the most powerful sources of auditory stimulation in the human brain is provided by Music. Listening to music is a complex process for the brain, since it triggers a sequel of cognitive and emotional components. The soothing power of music is well-established ${ }^{3}$. It has a unique link to our emotions, so can be an extremely effective stress management tool. Listening to music can have a tremendously relaxing effect on our minds and bodies, especially slow, quiet classical music. As music can absorb our attention, it acts as a distraction at the same time it helps to explore emotions. It has been known that severe stress lasting weeks or months can impair cell communication in the brain's learning and memory region, but this study provides the first evidence that short-term stress has the same effect ${ }^{1 \& 8}$. Cognitive function is often considered to encompass learning, memory and attention processes. Memory is a cognitive process that can be studied throughout life span. Cognitive skills are used to be able to adapt to an ever changing environment. For thousand years spatial memory has contributed to our knowledge and exploration of available resources in our surroundings. The acquisition and retention of a spatial navigation task is examined using a Morris Water Maze ${ }^{4}$. The hippocampal formation plays an important role in memory and learning. The Morris Water Maze (MWM) is a test of spatial learning for rodents that relies on distal cues to navigate from start locations around the perimeter of an open swimming arena to locate a submerged escape platform ${ }^{4}$.

\section{MATERIALS AND METHODS}

Animals: Wistar strain albino male and female, 20 days old rats were selected for this study. Experiments were carried out after obtaining Institutional Animal Ethical Committee approval (01/03/a/CPCSEA dated 25/10/2010). The animals were maintained under 12:12 hours dark: light cycle and controlled temperature (25 \pm $3^{\circ} \mathrm{C}$ ). Animals were fed with food (Amruth feeds, standard rat pellets) and water ad libitum. All the experiments were performed between 08:00-16:00 hrs.

Experimental design: In the present study, we have used totally 24 rats and random method was followed to select animals in to different groups. Animals were divided into four groups, $(n=6)$. Groups served as Normal control, Stress control and Stressed and then treated with instrumental Indian music therapy and instrumental Western music therapy. Rats in stress group received tube stress for duration of 2 hours for 10 days. Rats in group $3 \mathrm{rd}$ and $4^{\text {th }}$ received tube stress for duration of 2 hour for 10 days followed by instrumental Indian classical 
and western music therapy for 1 hour $^{9}$. The stress protocol involved placing the rats in a Plexiglas restraining tube (23.4 $\mathrm{cm}$ long and $7 \mathrm{~cm}$ in diameter) and exposing them to $1.6 \mathrm{~mA}$ inescapable shocks for $5 \mathrm{sec}$ each, with an average interval of $60 \mathrm{sec}$. The shocks were applied through electrodes taped to the tail. The animals were stressed between 8:00 and 10:00 A.M. and, after stressor termination, were returned to their home cages. Cages of stressed rats were placed on the opposite side of the room $(14 \times 12 \mathrm{ft})$ from the Home cage control animals. From day 21 st to 30th day, after stress induction, rats in group 2 were tested for cognitive parameter. Similarly, rats in group $3^{\text {rd }}$ and $4^{\text {th }}$ groups were also studied for the same parameter, from day 21 st to day 30th after therapeutic intervention. The details of test are as follows:

Morris water maze (MWM) :- The spatial learning abilities and memory of rats were assessed in the MWM task. The water maze consists of a circular pool (diameter, $1.5 \mathrm{~m}$; height, $60 \mathrm{~cm}$ ), filled with water $\left(26^{\circ} \mathrm{C} \pm 1^{\circ} \mathrm{C}\right)$ in which a square $(5 \mathrm{~cm})$ escape platform was hidden $1 \mathrm{~cm}$ below the surface of the $30 \mathrm{~cm}$. deep water. Water was made opaque by adding milk. The water maze was divided into four equal imaginary quadrants and escape platform was kept in a constant place, the center of the north-east quadrant. The maze was located in an experimental room containing relevant visual cues. Rats were trained for three consecutive days, daily sessions consisting of 3 trials with $5 \mathrm{~min}$. of inter trial interval. In each trial, rats were given $120 \mathrm{sec}$. to swim and find the escape platform. In case rats failed to find the platform within $120 \mathrm{sec}$, they were hand guided onto the platform. All animals were allowed to rest on the platform for $30 \mathrm{sec}$. A farthest starting location from platform was used in each trial. The time taken by each rat to reach the hidden platform was measured (transfer/escape latency). On $4^{\text {th }}$ day, probe trial was conducted during which the platform was removed from the maze and the rats were allowed to swim freely in the pool. The time spent in the target quadrant which has the platform in the previous trials, was served as measure of memory ${ }^{10-12}$.

\section{STATISTICAL ANALYSIS}

The comparison was carried out by Student's unpaired ' $T$ ' test. For neuro-cognitive test between groups comparisons were analyzed by Bonferroni Multiple comparison test. Differences were considered to be significant at probability value $(P)<0.05$.

\section{RESULTS}

The performance of experimental animals in the hidden platform test of MWM, in each group, is shown in for Day $1^{\text {st }}, 2$ nd $\& 3^{\text {rd }}$ are shown in Graph $1,2 \& 3$. During these trail sessions of three days, rats in all the groups learnt reaching the target quadrant and identifying the hidden platform there and escape from swimming except the rats in stress control group took more time to find the hidden platform compared to normal counterpart and therapeutic groups. Except stressed

Group of rats all other group of rats begin to identify the platform from second day, and continued to retain the learnt behavior and there was progressive learning in them. In stressed there was no significant progressive learning over days in them. During probe test $\left(4^{\text {th }}\right.$ day), the stressed rats spent lesser time in target quadrant when compare to normal. The statistical difference was observed in normal controls, stress control, and therapeutic group. Animals treated with Indian instrumental classical music therapy showed significant decrease in levels of anxiety as compared to group $2^{\text {nd }}$ and $4^{\text {th }}$. Animals treated with Western instrumental classical music therapy showed significant decrease in levels of anxiety as compared to group $2^{\text {nd }}$ but less significant as compared to group $3^{\text {rd }}$. On comparison between two therapeutic groups, the experimental animals in group $3^{\text {rd }}$ showed more significant decrease in anxiety levels and increased learning and memory capacity. Stress significantly increases the anxiety and also decreases learning and memory in the rats. However, significant $(\mathrm{p}<0.005)$ improvement is observed after the treatment with Indian instrumental classical music among stress induced rats.

Graph 1: a) NC with SC shows significant value 0.000 .

Graph 2: b) SC with WM shows significant value 0.000 .

Graph 3: c) SC with IM shows significant value 0.000 .

Graph4 : d) WM with IM shows significant value 0.005 .

\section{DISCUSSION}

The novel main finding of this study was that music listening during the post-stress stage can enhance cognitive recovery. Music is an integral part of rich Indian heritage and has come a long way since Vedic times since strong cultural and ancient history. It is perhaps the greatest force that unites humanity the world over. In today's world which is full of conflicts and tensions, it is music which is playing a significant role towards inner peace and harmony, transgressing man made frontiers and carrying a massage a piece. Music is also known to be great healer and has direct and indirect influence on physical and mental health of an individual. Of late music therapy is being used as an adjunct to medical line of therapy. In the present study we have evaluated of the music therapy in prevention of stress induced memory deficits in rats. Stress is known to impair the spatial learning and memory ${ }^{13}$.In the present study the restraint stressed animals showed memory impairment, which was evident in the Morris water maze test. Such memory impairment was attenuated by music therapy treatment. Chronic stress is known to cause memory impairments ${ }^{13}$. Neural basis for such impairment is the neuronal injury in the hippocampal region due to excitotoxicity ${ }^{14}$, alterations in the neurotransmitter levels in the brain regions. 
Alternatively, neuronal damage in this region may be mediated through increased glucocorticoids ${ }^{15}$. Stress results in increased oxidative stress and decreases antioxidant defense status in brain, which may form the basis for decreased memory ${ }^{16}$. In humans, music listening activates a wide-spread bilateral network of brain regions related to attention, semantic processing, memory, motor functions, and emotional processing ${ }^{3}$.The novel main finding of this study was that regular music listening during the stress period can enhance cognitive recovery. The study performed by Janata et al, confirms that music by its very nature, has strong connections to both attention and memory systems ${ }^{17}$. The Peretz and Zatorre had done studies on brain imaging which shows that listening to real polyphonic music calls for rule-based analysis and combination of sound patterns from multiple auditory streams, which naturally recruits bilateral temporal, frontal and parietal neural circuits underlying multiple forms of attention, working memory, semantic and syntactic processing, and imagery ${ }^{18}$.Music exposure also enhances emotional and cognitive functioning in healthy subjects and in various clinical patient groups. The potential role of music in neurological rehabilitation, however, has not been systematically investigated ${ }^{3}$. Music has a welldocumented effect on alleviating anxiety, depression and pain in patients with a somatic illness ${ }^{19-21}$.

Recent cognitive and neuropsychological studies suggest that it may also enhance a variety of cognitive functions, such as attention, learning, communication and memory, both in healthy subjects ${ }^{22-24}$ and in clinical conditions, such as dyslexia autism schizophrenia, multiple sclerosis, coronary artery disease and dementia ${ }^{26-28}$. In stroke rehabilitation, elements of music have previously been used as a part of physiotherapy and speech therapy to enhance the recovery of motor and speech functions. ${ }^{29}$ Music is also closely linked to emotions and arousal. Evidence suggests that music listening modulates emotional arousal as indexed by changes in electrodermal, cardiovascular and respiratory activity ${ }^{30-32}$. Listening to pleasant and relaxing music also enhances the recovery of cardiovascular and respiratory functions and decreases cortisol levels after stress ${ }^{33-35}$.Sarkamo et al. also documented that post stroke patients who listened to music daily, when compared to those who listened to audio books and those who listened to neither, "showed that recovery in the domains of verbal memory and focused attention improved significantly more in the music group than in the language and control groups. The music group also experienced less depressed and confused mood than the control group ${ }^{3}$.

Music therapy has been shown to reduce anxiety and depression in patients with a somatic illness ${ }^{19 \& 21}$. These findings suggest that music has an analgesic effect in reducing anxiety and directing attention away from the negative experience, thus helping to cope with emotional stress.

\section{CONCLUSION}

In summary, music has profound impact upon the human brain with subsequent effect on mental, physical and spiritual health and listening to music can facilitate a wide variety of cognitive and emotional functions. Indian instrumental classical music is one of the very cost effective, easily reachable remedy in reliving the negative effects of stress induced cognitive impairments. As always, while we are all free to choose freely which music we prefer, not all music is equally healthy - choose wisely!

\section{LIMITATIONS}

An important and difficult question still pertains to the neural mechanisms that can account for the beneficial effect of music on cognition.

\section{REFERENCES}

[1]. Jian Goa Yao, Yang Xia, Sheng-Jun Dai, Guang-Zhan Fang, Hua Guo, and De-Zhong Yao Enhancement of Spatial LearningMemory in developing rats via Mozart Music. Journal of Electronic Science and Technology of China. March 2009: (7) 47-49.

[2]. Das A, Rai.D,Dixit M,Patil G, Nath C. Effect of unpredictable stress on cognition and brain acetyl cholinesterase activity in adult and aged mice. Indian Journal of Pharmacology 2002; (34) 416-421.

[3]. Sarkamo Teppo, Tervaniemi Mari, Laitinen Sari,Forsblom Anita, Soinila Seppo, Mikkonen Mikko, Taina Autti, Heli M. Silvennoinen, Jaakko Erkkila, Matti Laine, Isabelle Peretz and Marja Hietanen Music listening enhances cognitive recovery and mood after middle cerebral artery stroke. Brain 2008;131(3) 866-876.4.

[4]. Vorhees, C.V., Williams, M.T., Nat Protocols. 2006, 848-858.

[5]. Vanitallie, T. B. (2002) Stress: a risk factor for serious illness. Metabolism 51, Suppl. 1, 40-45.

[6]. Kim, J. J. and Diamond, D. M. (2002) The stressed hippocampus, synaptic plasticity and lost memories. Nat. Rev. Neurosci. 3(6), 453-462.

[7]. Kien T. Nguyen, Terrence Deak, Stephanie M. Owens, Tadahiko Kohno, Monika Fleshner, Linda R. Watkins, and Steven F. Maier. Exposure to Acute Stress Induces Brain Interleukin-1及 Protein in the Rat. The Journal of Neuroscience, March 15, 1998, 18(6):2239-2246. [8]. Mizoguchi, K., Yuzurihara, M., Ishige, A., Sasaki, H., Chui, D. H., and Tabira, T. (2000)Chronic stress induces
impairment of spatial working memory because of prefrontal dopaminergic dysfunction. J. Neurosci. 20(4), 1568-1574

[9]. Yun Ha Joeng, Cheol Hyoung Park, Jongman Yoo, Ki Young Shin, Sung-Min Ahn, Hye-Sun Kim, Sang Hyung Lee, Piers C. Emson. Chronic stress accerlates Learning and Memory impairments and increase Amyloid deposition in APPv7171-CT100 transgenic mice. The FASEB Journal;2006 Feb,426-448.

[10]. Noam M, Carla G, Giuseppina T, Nicoletta G, Dennis D, Daniel T et.al: Reversible antisense inhibition of Shaker-like Kv1.1 potassium channel expression impairs associative memory in mouse and rat. PNAS 1997,94:4430-4434

[11]. Expand+Walther T, Balschun D, Voigt J, Fink H, Zuschratter W, Birchmeier C, et al. Sustained long term potentiation and anxiety in mice lacking the Mas Protooncogene J Biol Chem, 1998, 273: 11867-11873. doi:10.1074/jbc.273.19.11867.

[12]. Vivek Kumar Sharma, Morris Water Maze - A Versatile Cognitive Tool. Biosci Tech, Vol 1 (1),2009, 15-19.

[13]. Sunanda, Rao BS, Raju TR.Chronic restraint stress impairs acquisition and retention of spatial memory task in rats .Current Science 2000; 79:1581-1584. 
[14]. Sunanda, Meti BL, Raju TR. Entorhinal cortex lesioning protects hippocampal CA3 neurons from stress-induced damage. Brain Research1997; 770(1-2)302-306.

[15]. McEwen BS. Physiology and neurobiology of stress and adaptation: central role of the brain. Physiol.Rev 2007; 87(3): 873-904.

[16]. Zaidi SM, Banu N.Antioxidant potentials of vitamin A, E, and C in modulation oxidative stress in rat brain. Clin.Chim Acta 2004; 340(1-2):229-33.

[17]. Janata P, Tillmann B, Bharucha JJ. Listening to polyphonic music recruits domain-general attention and working memory circuits. Cogn Affect Behav Neurosci (2002) 2:121-40.

[18]. Peretz I, Zatorre RJ. Brain organization for music processing. Annu Rev Psychol (2005) 56:89-114.

[19]. Cassileth BR, Vickers AJ, Magill LA. Music therapy for mood disturbance during hospitalization for autologous stem cell transplantation: a randomized controlled trial. Cancer (2003) 98:2723-9.

[20]. Cepeda MS, Carr DB, Lau J, Alvarez H. Music for pain relief. Cochrane Database Syst Rev (2006) 004843.

[21]. Siedliecki SL, Good M. Effect of music on power, pain, depression and disability. J Adv Nurs (2006) 54:553-62.

[22]. Wallace WT. Memory for music: effect of melody on recall of text. J Exp Psychol Learn Mem Cogn (1994) 20:1471-85.

[23]. Thompson WF, Schellenberg EG, Husain G. Arousal, mood, and the Mozart effect. Psychol Sci (2001) 12:248-51

[24]. Thompson RG, Moulin CJ, Hayre S, Jones RW. Music enhances category fluency in healthy older adults and Alzheimer's disease patients. Exp Aging Res (2005) 31:91-9.

[25]. Schellenberg EG, Nakata T, Hunter PG, Tamoto S. Exposure to music and cognitive performance: Tests of children and adults. Psychol Music (2007) 35:5-19.

[26]. Overy K. Dyslexia and music. From timing deficits to musical intervention. Ann NY Acad Sci (2003) 999:497-505.

[27]. Gold C, Wigram T, Elefant C. Music therapy for autistic spectrum disorder. Cochrane Database Syst Rev (2006) 004381

[28]. Talwar N, Crawford MJ, Maratos A, Nur U, McDermott O, Procter S. Music therapy for in-patients with schizophrenia: exploratory randomised controlled trial. Br J Psychiatry (2006) 189:405-9.

[29]. Thaut MH, Peterson DA, McIntosh GC. Temporal entrainment of cognitive functions: Musical mnemonics induce brain plasticity and oscillatory synchrony in neural networks underlying memory. Ann NY Acad Sci (2005) 1060:243-54

[30]. Khalfa S, Isabelle P, Jean-Pierre B, Manon R. Event-related skin conductance responses to musical emotions in humans. Neurosci Lett (2002) 328:145-9.

[31]. Bernardi L, Porta C, Sleight P. Cardiovascular, cerebrovascular, and respiratory changes induced by different types of music in musicians and non-musicians: the importance of silence. Heart (2006) 92:445-52.

[32]. Gomez P, Danuser B. Relationships between musical structure and psychophysiological measures of emotion. Emotion (2007) 7:377-87.

[33]. Khalfa S, Dalla Bella S, Roy M, Peretz I, Blondin JP. Effects of relaxing music on salivary cortisol level after psychological stress. Ann NY Acad Sci (2003) 999:374-6.

[34]. Leardi S, Pietroletti R, Angeloni G, Necozione S, Ranalletta G, Del Gusto B. Randomized clinical trial examining the effect of music therapy in stress response to day surgery. Br J Surg (2007) 94:943-7.

[35]. Sokhadze EM. Effects of music on the recovery of autonomic and electrocortical activity after stress induced by aversive visual stimuli. Appl Psychophysiol Biofeed (2007) 32:31-50.

\section{Graph 1:}

\section{Graph 2:}

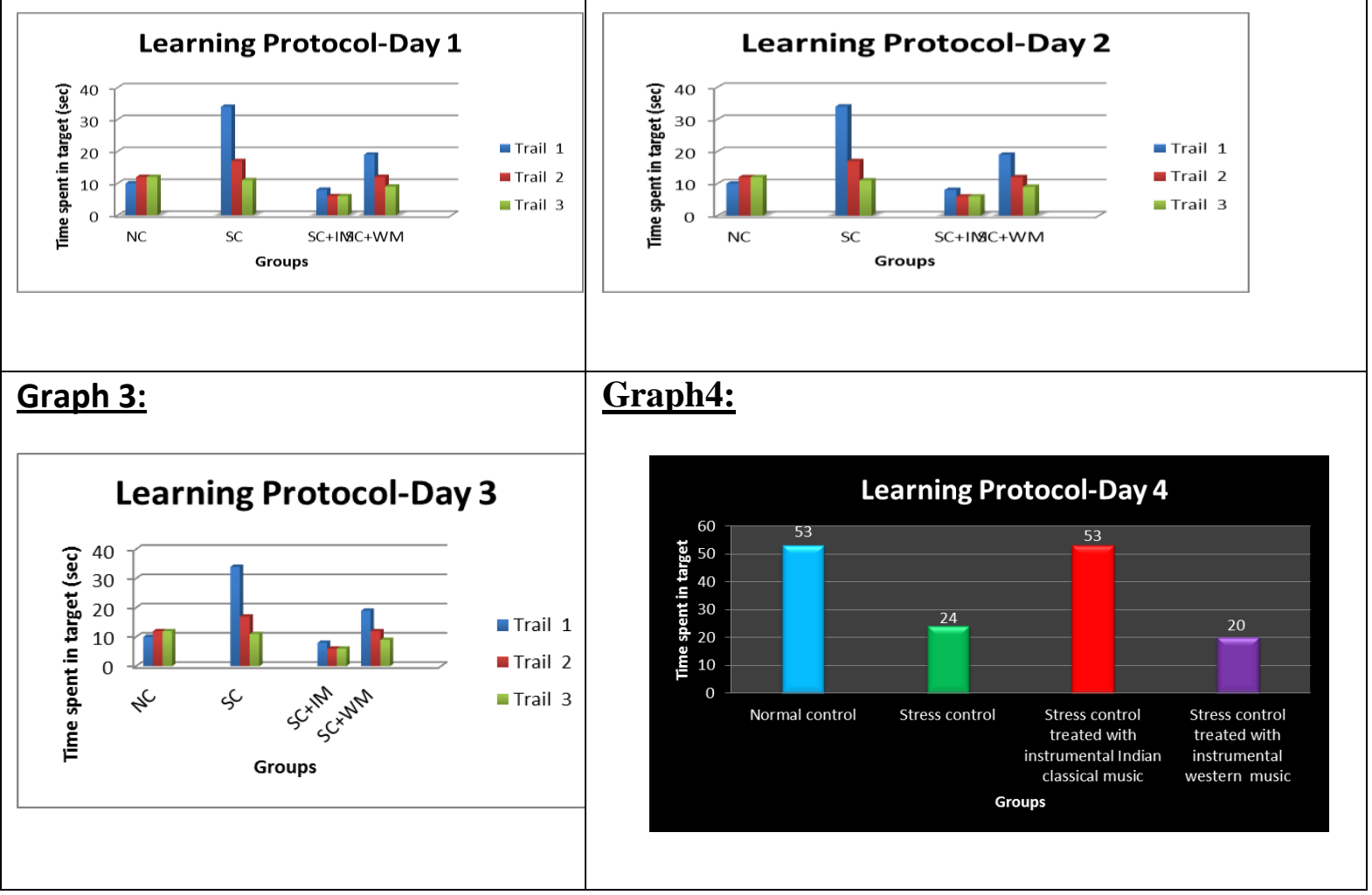

